\title{
TEORIA E PRÁTICA DA ADAPTAÇÃO: DA FIDELIDADE À INTERTEXTUALIDADE
}

Robert Stam

New York University

\section{Resumo}

$\mathrm{O}$ artigo analisa as formas como as adaptações de filmes a partir de romances têm sido vistas como um processo de perda, em que o romance ocupa um lugar privilegiado. Confrontando esta perspectiva, o ensaio propõe uma linguagem alternativa aos estudos de adaptação. A partir do conceito de dialogismo de Bakhtin e da definição de intertextualidade de Genette, torna-se possível pensar em adaptação em termos de uma prática intertextual.

Palavras-chave: adaptação; intertextualidade.

Neste ensaio, eu gostaria de propor uma linguagem alternativa para falar sobre a adaptação de romances ao cinema. ${ }^{1} \mathrm{~A}$ linguagem convencional da crítica sobre as adaptações tem sido, com frequência, profundamente moralista, rica em termos que sugerem que o cinema, de alguma forma, fez um desserviço à literatura. Termos como "infidelidade", "traição", "deformação", "violação", "abastardamento", "vulgarização", e "profanação" proliferam no discurso sobre adaptações,

\begin{tabular}{|l|l|l|l|l|}
\hline Ilha do Desterro & Florianópolis & $n^{\circ} 51$ & p. 019-053 & jul./dez. 2006 \\
\hline
\end{tabular}


cada palavra carregando sua carga específica de ignomínia. "Infidelidade" carrega insinuações de pudor vitoriano; "traição" evoca perfídia ética; "abastardamento" conota ilegitimidade; "deformação" sugere aversão estética e monstruosidade; "violação" lembra violência sexual; "vulgarização" insinua degradação de classe; e "profanação" implica sacrilégio religioso e blasfêmia.

Embora seja fácil imaginar um grande número de expressões positivas para as adaptações, a retórica padrão comumente lança mão de um discurso elegíaco de perda, lamentando o que foi "perdido" na transição do romance ao filme, ao mesmo tempo em que ignora o que foi "ganhado". Em uma diatribe de 1926, Virginia Woolf, por exemplo, denunciou veementemente as adaptações que reduziam as complexas nuances da idéia de "amor" num romance a "um beijo", ou representavam a "morte" de forma literal, como um "carro funerário". ${ }^{2}$ Com demasiada frequência, o discurso sobre a adaptação sutilmente re-inscreve a superioridade axiomática da literatura sobre o cinema. Uma parte excessiva do discurso, eu argumentaria, tem focado a questão um tanto quanto subjetiva da qualidade das adaptações, ao invés de assuntos mais interessantes como: 1) o estatuto teórico da adaptação, e 2) o interesse analítico das adaptações. Meu objetivo aqui, portanto, não é o de corrigir avaliações errôneas de adaptações específicas, mas sim desconstruir a doxa não declarada que sutilmente constrói o status subalterno da adaptação (e da imagem cinematográfica) vis-à-vis os romances (e o mundo literário), para então apontar perspectivas alternativas.

\section{As raízes do preconceito}

Embora o poder persuasivo da suposta superioridade da literatura ao filme possa ser parcialmente explicada pelo fato inegável de que muitas adaptações baseadas em romances importantes são medíocres ou mal orientadas, ele também deriva, eu argumentaria, das pressuposições profundamente enraizadas e freqüentemente inconscientes sobre as relações entre as duas artes. $\mathrm{O}$ senso intuitivo da inferioridade 
da adaptação deriva, eu especularia, de uma constelação de preconceitos primordiais. Em outros textos eu resumi esses preconceitos nos seguintes termos: 1) antiguidade (o pressuposto de que as artes antigas são necessariamente artes melhores); 2) pensamento dicotômico ( o pressuposto de que o ganho do cinema constitui perdas para a literatura);3) iconofobia (o preconceito culturalmente enraizado contra as artes visuais, cujas origens remontam não só às proibições judaicoislâmico-protestantes dos ícones, mas também à depreciação platônica e neo-platônica do mundo da aparências dos fenômenos); 4) logofilia, (a valorização oposta, típica de culturas enraizadas na "religião do livro", a qual Bakhtin chama de "palavra sagrada"dos textos escritos); 6) anti-corporalidade, um desgosto pela "incorporação" imprópria do texto fílmico, com seus personagens de carne e osso, interpretados e encarnados, e seus lugares reais e objetos de cenografia palpáveis; sua carnalidade e choques viscerais ao sistema nervoso; 6) a carga de parasitismo (adaptações vistas como duplamente "menos": menos do que o romance porque uma cópia, e menos do que um filme por não ser um filme "puro").

\section{O impacto do pós}

Os desenvolvimentos teóricos do estruturalismo e do pós-estruturalismo, entretanto, subvertem muitos desses preconceitose, deste modo, causam impacto indireto em nossa conversa sobre adaptação. A semiótica estruturalista das décadas de 1960 e 1970 tratava todas as práticas de significação como sistemas compartilhados de sinais que produzem "textos" dignos do mesmo escrutínio cuidadoso dos textos literários, abolindo, desta forma, a hierarquia entre o romance e o filme. A teoria da intertextualidade de Kristeva (enraizada e traduzindo literalmente o "dialogismo" de Bakhtin) e a teoria da "intertextualidade" de Genette, similarmente, enfatizam a interminável permutação de textualidades, ao invés da "fidelidade" de um texto posterior a um modelo anterior, e desta forma também causam impacto em nosso pensamento sobre adaptação. A nivelação provocativa da hierarquia entre 
crítica literária e literatura de Roland Barthes, do mesmo modo, funciona analogamente para resgatar a adaptação ao cinema como uma forma de crítica ou "leitura" do romance, que não está necessariamente subordinada a ele ou atuando como um parasita de sua fonte.

Embora a teoria da intertextualidade certamente tenha reformulado os estudos da adaptação, outros aspectos do pós-estruturalismo ainda não haviam sido levados em conta na re-elaboração do status e prática da adaptação. A desconstrução de Derridá, por exemplo, desfez binarismos excessivamente rígidos em favor da noção de "mútua invaginação". A desconstrução também desmantela a hierarquia do "original" e da "cópia". Numa perspectiva derridiana, o prestígio aural do original não vai contra a cópia, mas é criado pelas cópias, sem as quais a própria idéia de originalidade perde o sentido. $\mathrm{O}$ filme enquanto "cópia", ademais, pode ser o "original" para "cópias" subseqüentes. Uma adaptação cinematográfica como "cópia", por analogia, não é necessariamente inferior à novela como "original". A crítica derridiana das origens é literalmente verdadeira em relação à adaptação. O "original" sempre se revela parcialmente "copiado" de algo anterior; A Odisséia remonta à história oral anônima, Don Quixote remonta aos romances de cavalaria, Robinson Crusoé remonta ao jornalismo de viagem, e assim segue ad infinitum.

A interrogação pós-estruturalista do sujeito unificado, entretanto, fissura o autor como o ponto de origem da arte. Do ponto de vista lacaniano, a individualidade é um "ego-artefato", uma ficção discursiva baseada num bricabraque de impulsos de identidade, sempre no limiar da dissolução. A psique apenas aparenta estar unida, consistente e centrada. A noção de Bakthin de autor e personagem como multidiscursivos e resistentes à unificação, similarmente, problematiza tanto autor e personagem enquanto entidades estáveis e unitárias. Diferente das noções de unidade orgânica da nova crítica, a crítica pósestruturalista enfatiza as fissuras, as contradições insolúveis e os excessos do texto. E se os autores são fissurados, fragmentados, multidiscursivos, dificilmente "presentes" até para eles mesmos, o analista 
poderia perguntar: como pode uma adaptação comunicar o "espírito" ou a "presença individual" da intenção autorial?

A concepção bakthiniana pós-estruturalista do autor como um orquestrador de discursos pré-existentes, junto com a desvalorização realizada por Focault do autor em favor de uma "anonimidade penetrante do discurso", abriu caminho para uma abordagem não-originária para todas as artes. A atitude de Bakthin em relação ao autor literário como alguém que habita "território inter-individual" sugeriu a desvalorização da "originalidade" artística. Já que as palavras, incluindo as palavras literárias, sempre vêm "da boca de outrem", a criação artística nunca é ex nihilo, mas sim baseada em textos antecedentes. Apesar da comparação perene do artista com Deus, demiurgo, criador, progenitor, ou legislador não reconhecido da humanidade, o verdadeiro papel do artista, para Bakthin, está envolvido em interações mais modestas, humanas e sublunares. Como o que Bakthin chama de "construção híbrida", a expressão artística sempre mistura as palavras do próprio artista com as palavras de outrem. A adaptação, também, deste ponto de vista, pode ser vista como uma orquestração de discursos, talentos e trajetos, uma construção "híbrida", mesclando mídia e discursos, um exemplo do que Bazin na década de 1950 já chamava de cinema "misturado" ou "impuro". A originalidade completa não é possível nem desejável. E se a "originalidade" na literatura é desvalorizada, a "ofensa" de "trair" essa originalidade, através de, por exemplo, uma adaptação "infiel", é muito menos grave.

Falando mais genericamente, o afastamento da "obra" para noções mais difusas tais quais "textualidade", "ecriture", e "literário" facilita uma retração de fronteiras que permite categorias mais inclusivas, dentro das quais a adaptação se torna apenas outra "zona" num mapa maior e mais variegado. Conforme a teoria descobre a "literaridade" de fenômenos não-literais, qualidades consideradas como literárias se revelam cruciais para o discurso e prática não literários. A inclusão do subliterário no literário, a reformulação da própria categoria do literário como uma configuração instável e sem um fim determi- 
nado, neste sentido, produz uma visão mais tolerante do que comumente é visto como um gênero "subliterário"e "parasitário" - a adaptação.

Outros movimentos e tendências teóricas também rebaixam indiretamente o texto literário de sua posição de autoridade opressiva e assim apontam para uma possível reconceitualização da adaptação. O campo interdisciplinar de "estudos culturais", por exemplo, se mostra menos interessado em estabelecer hierarquias verticais de valor do que em explorar relações "horizontais" entre mídias fronteiriças. Sob uma perspectiva cultural, a adaptação faz parte de um espectro de produções culturais niveladas e, de forma inédita, igualitárias. Dentro de um mundo extenso e inclusivo de imagens e simulações, a adaptação se torna apenas um outro texto, fazendo parte de um amplo contínuo discursivo.

A narratologia, uma forte tendência dentro dos estudos de cinema desde os anos 1970, enquanto isso, concede centralidade cultural à narrativa em geral, em oposição à narrativa literária isoladamente. Para a narratologia, os seres humanos usam as histórias como sua principal forma de fazer sentido das coisas, não apenas nas ficções escritas mas o tempo todo, e em todos os níveis. Os narratologistas vêem a história como um espécie de material genético ou DNA a ser manifestado no corpo de textos específicos; eles falam de núcleos ou substrato narrativos que existem "abaixo" de mídias específicas. A narrativa é protéica, assumindo uma variedade de formas, das narrativas pessoais da vida quotidiana até as miríades de formas de narrativa pública - quadrinhos, histórias, comerciais de TV, as notícias da noite e, claro, o cinema. ${ }^{3}$ A literatura e o romance não mais ocupam um lugar privilegiado; a adaptação, por implicação, assume um lugar legítimo ao lado do romance, como apenas mais um meio narratológico.

A teoria da recepção também reafirma, indiretamente, o respeito pela adaptação enquanto forma. Para a teoria da recepção, um texto é um evento cujas indeterminações são completadas e se tornam verdadeiras quando lido (ou assistido). Ao invés de ser mero "retrato" de uma realidade pré-existente, tanto o romance como o filme são expressões comunicativas, situadas socialmente e moldadas histori- 
camente. Como o pós-estruturalismo, a teoria da recepção também enfraquece a noção de um núcleo semiótico, um núcleo de significado, atribuído às novelas, cujas adaptações presumidamente devem "capturar" ou "trair", desta forma abrindo espaço para a idéia de que a adaptação complementa as lacunas de um texto literário. $\mathrm{O}$ texto polifônico, dialógico, heteroglóssico e plural do romance, para usar a linguagem de Bakhtin, se torna suscetível às múltiplas e legítimas interpretações, incluindo a forma de adaptações como leituras ou interpretações. Além do mais, a teoria contemporânea assume que os textos não se conhecem a si mesmos, e portanto busca o que não está dito (o non-dit) no texto. As adaptações, neste sentido, podem ser vistas como preenchendo essa lacuna do romance que serve como fonte, chamando a atenção para suas ausências estruturais. Esse "preenchimento" é comum especialmente em adaptações de textos há muito consagrados, como Robinson Crusoé, onde a passagem do tempo faz com que o leitor/adaptador fique cético sobre as premissas e suposições básicas do romance.

Pensadores de outras áreas, como a filosofia, também já questionaram a hierarquia que coloca a literatura e a filosofia "acima" do cinema. Para Gilles Deleuze, o cinema é em si um instrumento filosófico, um gerador de conceitos que traduz o pensamento em termos áudiovisuais, não em linguagem mas em blocos de movimento e duração. A visão deleuziana rejeita a visão tradicional de que o cinema, ao contrário da literatura e da filosofia, não era "capaz de pensamento". Deleuze não "aplica" conceitos filosóficos ao cinema; mais propriamente, ele trabalha com os conceitos que o cinema em si dá origem. No cinema o pensamento em movimento encontra a imagem em movimento. De fato, Deleuze está interessado em comensurabilidades e interconexões entre a história da filosofia e a história do cinema, os movimentos conceituais que ligam Eisenstein a Hegel, por exemplo, ou o cinema moderno a Nietzche ou Bergson.

A teoria performativa, por sua vez, oferece uma linguagem alternativa para tratar da adaptação, pela qual tanto o romance quanto a adaptação viram performances, um verbal, e o outro visual, verbal e 
acústico. O conceito de proferição performativa, desenvolvido nos anos 1950 pelo filósofo britânico J. L. Austin, e subseqüentemente retrabalhado por Jacques Derrida e Judith Butler, está enraizado na distinção de Austin entre proferições constativas - que fazem uma afirmação, descrevem o estado das coisas, e são verdadeiras ou falsas, e as proferições performativas, que não são verdadeiras ou falsas mas na verdade realizam a ação à qual elas se referem. Assim como a proferição literária cria a situação à qual ela se refere - mais do que meramente imitar algum estado de coisas pré-existente - poder-se-ia dizer que a adaptação cinematográfica cria uma nova situação áudio-visual-verbal, mais do que meramente imitar o velho estado de coisas como representado pelo romance original. A adaptação assim molda novos mundos mais do que simplesmente retrata/trai mundos antigos.

Desmistificado por Marx e pelas correntes estruturalistas, feministas, pós-estruturalistas e pós-colonialistas, a aura da literatura aparentemente foi diminuída. Um corolário, o "sacrilégio"da adaptação blasfema se tornou proporcionalmente menos escandaloso. Nem o texto literário nem o autor mantêm a "autoridade de controle legal" sobre ramificações intertextuais. O impulso desconstrutivo, comum a muitas das correntes intelectuais citadas aqui, tendeu a desfazer hierarquias falsas ou logocêntricas (homem/mulher; mente/corpo; branco/negro; heterossexual/homossexual; falado/escrito), servindo, desta forma, mesmo que apenas por implicação, para enfraquecer igualmente as hierarquias da literatura sobre o cinema e da fonte sobre a adaptação. A descentralização feminista e multicultural do cânon, similarmente, relativizou a superioridade assumida de textos de romances clássicos, enfraquecendo ainda mais o valor de culto do "original". A literatura é vista agora como uma categoria construída histórica e ideologicamente, "mundana" no sentido dado por Edward Said. Ela foi trazida de volta à terra, distante do lugar em que o culto da arte a colocou.

Se "fidelidade" é um termo inadequado, qual termo seria mais adequado? Ao invés dos termos denegritivos para adaptação tais quais "traição" e "infidelidade", poder-se-ia falar em um modelo Pygmalion 
(N.T. Título de peça de Bernard Shaw), pelo qual a adaptação trás o romance "à vida", ou de um modelo "ventriloqual", onde o filme "empresta voz" aos personagens mudos do romance, ou de modelo "alquímico", onde a adaptação se transforma em ouro. Ou, bebendo na fonte da tradição religiosa da África Ocidental, poder-se-ia falar em modelo de "possessão", pelo qual o orixá (espírito) do texto literário desce até o corpo/cavaleiro da adaptação cinematográfica. O que alguns demonizaram como a incorporação grosseira do meio cinematográfico poderia ser "redimido" através do que Kamilla Elliott chama de "o modelo incarnacional", isto é, a idéia cristã de que graças à adaptação a "Palavra" do romance é "feita Carne", enquanto a Bíblia Judia (nos termos cristãos o "Velho Testamento") é "realizada" pelo Novo Testamento do filme. ${ }^{4}$

A teoria da adaptação tem à sua disposição, até aqui, um amplo arquivo de termos e conceitos para dar conta da mutação de formas entre mídias - adaptação enquanto leitura, re-escrita, crítica, tradução, transmutação, metamorfose, recriação, transvocalização, ressuscitação, transfiguração, efetivação, transmodalização, significação, performance, dialogização, canibalização, reimaginação, encarnação ou ressurreição. (As palavras com o prefixo "trans" enfatizam a mudança feita pela adaptação, enquanto aquelas que começam com o prefixo "re" enfatizam a função recombinante da adaptação). Cada termo joga luz sobre uma faceta diferente da adaptação. O termo para adaptação enquanto "leitura" da fonte do romance, sugere que assim como qualquer texto pode gerar uma infinidade de leituras, qualquer romance pode gerar um número infinito de leituras para adaptação, que serão inevitavelmente parciais, pessoais, conjunturais, com interesses específicos. A metáfora da tradução, similarmente, sugere um esforço íntegro de transposição intersemiótica, com as inevitáveis perdas e ganhos típicos de qualquer tradução. ${ }^{5}$

Praticamente toda a teoria e análise literária relacionada direta ou indiretamente com a "intertextualidade" - da idéia modernista brasileira de "antropofagia" à noção de significação de Henry Louis Gates até a "ansiedade da influência" de Harold Bloom - é relevante para o 
filme e para a adaptação. Aqui, no entanto, vou me concentrar na produtividade analítica de alguns conceitos desenvolvidos por Mikahil Bakhtin e Gerar Genette.

$\mathrm{O}$ "dialogismo" bakthiniano se refere no sentido mais amplo, às infinitas e abertas possibilidades geradas por todas as práticas discursivas da cultura, a matriz de expressões comunicativas que "alcançam" o texto não apenas através de citações reconhecíveis mas também através de um processo sutil de retransmissão textual. Qualquer texto que tenha "dormido com" outro texto, como disse um gracejador pós-moderno, também dormiu com todos os outros textos que o outro texto já dormiu. É essa "doença" textualmente transmitida que caracteriza o troca-troca que Derridá chamou de "disseminação". O dialogismo, em seu sentido amplo, é central não apenas para o texto canônico da tradição literária e filosófica, mas também para os textos não-canônicos. É central, além do mais, até para expressões que não são convencionalmente pensadas como "texto". Embora seja, num sentido, um truísmo conhecido de Montaigne, que escreveu que "mais livros já foram escritos sobre outros livros do que qualquer outro assunto", o dialogismo bakhtiniano é bem mais radical uma vez que ele se aplica tanto para a fala cotidiana quanto para a tradição literária e artística. Indo muito além do rastreamento filológico de "fontes" e "influência", Bakhtin persegue uma disseminação mais difusa de idéias enquanto elas penetram e inter-vitalizam toda a "série", literária e não literária, enquanto elas são geradas pelas "correntes profundas e poderosas da cultura".

Noções de "dialogismo" e "intertextualidade", então, nos ajudam a transcender as contradições insolúveis da "fidelidade" e de um modelo diádico que exclui não apenas todos os tipos de textos suplementares mas também a resposta dialógica do leitor/espectador. Um texto como Don Quixote remonta ao romance de cavalaria, faz um paralelo com o contemporâneo Lope de Vaga, e antecipa Kathy Acker e Orson Welles e O Homem de La Mancha. Robinson Crusoé remonta à Bíblia, faz um paralelo com a literatura de viagem, e antecipa $O$ Náufragoe $O$ Sobrevivente. Partindo de Bakhtin e Kristeva, Gerard Genette em Palimpsestes (1982) fornece outros conceitos analíticos úteis. Embora 
Genette não trate do cinema, seus conceitos podem ser extrapolados para o cinema e a adaptação. Ao invés de manter o termo "intertextualidade", Genette propõe o termo mais inclusivo "transtextualidade", referindo-se a "tudo aquilo que coloca um texto em relação com outros textos, seja essa relação manifesta ou secreta". Genette postula cinco tipos de relações transtextuais, todos eles sugestivos para a teoria e análise da adaptação.

O primeiro tipo de transtextualidade é a "intertextualidade", ou o "efeito de co-presença de dois textos" na forma de citação, plágio e alusão. A intertextualidade, talvez a mais óbvia das categorias, chama atenção para o papel genérico da alusão e da referência em filmes e romances. Esse intertexto pode ser oral ou escrito. Freqüentemente o intertexto não está explícito mas é, mais precisamente, as referências a conhecimentos anteriores que são assumidamente conhecidos. Isso é verdade especialmente para textos geradores de cultura como as bíblias judia e cristã. Pense por exemplo na presença da história do Êxodus em Vinhas da Ira (Grapes of Wrath), ou em todas as variações cômicas / satíricas da última ceia de Cristo (Desde a Viridiana de Bunuel e $A$ História do Mundo Parte I de Mel Brooks até Monty Python ao Vivo no Hollywood Bowl. A intertextualidade pode até ser transmitida por objetos físicos, como mostra Gabriel Moses em sua análise do papel da bíblia como um objeto literal em filmes.

A "alusão" no cinema também pode tomar formas distintas específicas para essa mídia. No cinema, o movimento de câmera pode ser uma alusão, como vemos na extensa série de longas tomadas virtuosas, até exibicionistas, de grua e steadicam-indo desde A Marca da Maldade de Welles até $O$ Jogador de Altman e Boogie Nights - Prazer Sem Limites de Paul Thomas Anderson - que fazem parte das aberturas vistosas de toda uma série de filmes, cada um conscientemente se referindo aos anteriores, e cada um tirando partido da novas tecnologias disponíveis.

O segundo tipo de transtextualiade de Genette é a "paratextualidade", ou a relação, dentro da totalidade de uma obra literária, entre o próprio texto e seu "paratexto" - títulos, prefácios, pósfacios, 
epígrafes, dedicatórias, ilustrações, e até as sobrecapas e autógrafos, em suma, todas as mensagens acessórias e comentários que circundam o livro e que às vezes se tornam virtualmente indistinguíveis dele. No filme, embora Genette não o mencione, a "paratextualidade" pode evocar todos esses materiais soltos do texto, tal qual pôsteres, trailers, resenhas, entrevistas com o diretor e assim por diante.

Com a paratextualidade tanto a tecnologia quanto o comércio podem exercer um papel. Diversas versões de filmes em DVD (por exemplo, $O$ Diário de Bridget Jones) incluem seqüências que foram filmadas mas não incluídas na versão final. Esse recurso paratextual permite ao espectador do DVD literalmente "visionar" versões alternativas da adaptação, podendo lamentar (ou aplaudir) a perda de uma seqüência filmada. Um DVD da Criterion dedicado à adaptação de Godard para o romance $O$ Desprezo, de Moravia, inclui entrevistas com Godard, com Raoul Coutard, com Fritz Lang, junto com materiais visuais sobre a atriz Briggitte Bardot. Outros DVDs revelam a cena filmada pelos diretores mas excluída da versão de lançameneto - por exemplo, a versão mais longa de Apocalypse Now - dando assim uma idéia da "versão do diretor". Esses materiais paratextuais inevitavelmente remodelam nossa experiência e compreensão do próprio texto. Mas o "paratexto" também toma formas mais mercadológicas. No caso dos grandes sucessos de Hollywood, incluindo aqueles baseados em fontes pré-existentes como romances ou histórias em quadrinhos, o texto acaba sendo inundado por um paratexto comercial. O filme se torna uma espécie de marca ou franchise, desenhada para gerar não apenas seqüências mas também produtos de consumo subordinados como brinquedos, músicas, livros e outros produtos sinérgicos dos diversos tipos de mídia. As adaptações de Harry Potter, por exemplo, se tornam o que Peter Bart chama de um "megafranchise", arrecadando bilhões de dólares.

O terceiro tipo de interterxtualidade de Genette é a "metatextualidade", ou a relação crítica entre um texto e outro, seja quando o texto comentado é citado explicitamente ou quando é evocado silenciosamente. Aqui nós podemos enfatizar tanto os aspectos 
de "relação crítica" quanto de "evocação silenciosa" da categoria. O primeiro termo evoca todas aquelas adaptações que criticam ou de alguma forma expressam hostilidade, seja pelo romance original ou por adaptações anteriores. Stephen Schiff e Adrien Lyne, por exemplo, viam a versão antecedente de Lolita como um exemplo de "tudo que deveria ser evitado" em sua própria versão. ${ }^{7}$ (A noção de adaptações metatextuais obviamente não é compatível com o discurso de "fidelidade"). Desta forma, "metatextualidade" evoca toda a tradição de versões crítica de romances, seja na literatura ou no cinema. El Otro Francisco, de Sergio Giral, por exemplo, realiza uma crítica devastadora de Francisco, o romance abolicionista e sentimental cubano que lhe serve de fonte. Uma tendência recente na literatura é reescrever um romance da perspectiva de personagens secundários ou até imaginários. Desta forma, temos Robinson Crusoé re-escrito a partir da perspectiva de Susan Barton (Foe, de Coetzie), Moby Dick da perspectiva da mulher do Capitão Ahab (Ahab's Wife, de Sena Naslund), Lolita da perspectiva de Lolita (Lo's Diary, de Pia Pera), Don Quixote da perspectiva de uma Quixote feminina (Don Quixote, de Kathy Acker), e EO Vento Levou da perspectiva dos escravos (The Wind Done Gone, de Alice Randall). As permutações possíveis são infinitas, já que qualquer romance poderia ser re-escrito da perspectiva de um personagem diferente: uma versão ecológica de Moby Dick poderia nos trazer o Capitão Ahab da perspectiva da baleia. Adaptações cinematográficas, eu argumentaria, devem ser vistas num continuum, do qual fazem parte essas "versões".

Em termos de uma fonte não mencionada, ou "evocada silenciosamente", no entanto, a "metatextualidade" nos faz lembrar aqueles filmes que têm uma relação mais difusa e não declarada com o romance original ou até mesmo com todo um gênero de literatura. Maria Tortajada argumenta que os filmes de Eric Rohmer, por exemplo, retrabalham a tradição francesa da libertinagem como exemplificada pelo romance As Ligações Perigosas, mesmo que Rohmer nunca tenha adaptado Laclos. A Idade do Ouro, de Buñuel, similarmente, não é uma "adaptação" de Marques de Sade, no entanto Alan Weiss argumenta 
que 120 dias de Sodoma é uma fonte textual/estrutural invisível no filme. (Na coletânea Companion to Film and Literature).

A "metatextualidade" também evoca o caso das "adaptações não identificadas". Tem sido uma prática comum da indústria do cinema comercial na Índia fazer "adaptações não identificadas". De acordo com Nitin Govil, nos anos 90 três versões de Uma Linda Mulher e quatro vesões de Ghost - do Outro Lado da Vida estavam sendo feitas. ${ }^{8}$ Outros exemplos poderiam incluir as relações intertextuais não explícitas entre Charlote Bronte e O Piano de Jane Campion, ou entre Forrest Gump-oContador de Histórias e Cândido, de Voltaire, ou As Patricinhas de Beverly Hills como uma adaptação não declarada (a não ser nas entrevistas) de Emma, de Jane Austen. Enquanto Emma se refere a um personagem do romance de Jane Austen, As Patricinhas de Beverly Hills evoca a gíria adolescente de um meio particular de Los Angeles num período histórico específico. Algumas adaptações, como Bom Trabalho (1999), de Claire Denis, mal podem ser reconhecidas como adaptações. Nele, o romance que serve como fonte-Billy Budd, de Melville, se torna uma matriz inspiradora de motivos temáticos e estilísticos. Os "marinheiros bronzeados" de Melville tornam-se os soldados de peito nu, enquanto a cena é deslocada para outro local, o continuum do mundo do Atlântico negro - a África. O romance se torna um trampolim, menos para uma adaptação do que para um poema-tonal estilizado, matizado com alusões a outros filmes (OPequeno Soldado, de Godard) e outras artes (a ópera Billy Budd, de Benjamin Britten).

O quarto tipo de intertextualidade de Gennette é a "arquitextualidade", ou as taxonomias genéricas sugeridas ou refutadas pelos títulos e subtítulos de um texto. Num primeiro olhar, essa categoria parece irrelevante para a adaptação, uma vez que as adaptações, geralmente, simplesmente adotam o título do romance em questão. Mas, como vimos aqui, existem as "adaptações não identificas" (As Patricinhas de Beverly Hills) e as adaptações genéricas e difusas (Rohmer). Existem também as adaptações renomeadas, como quando Coppola adapta No Coração das Trevas, de Conrad, para Apocalypse Now, sendo que o título é uma clara inversão em cima da 
peça contra-cultural Paradise Now, do Living Theatre. A "arquitextualidade" também diz respeito às adaptações com nomes enganosos. Rameau's Nephew, de Michael Snow, por exemplo, não traz nada da história do personagem do romance-diálogo de Diderot, estimulando assim o espectador literato a procurar por outras conexões com Diderot. (Estaria Snow sendo tão inovador em termos técnicos/estilísticos quanto Diderot era em termos literários, por exemplo?). Ações judiciais que alegam que determinado filme foi baseado em uma fonte não reconhecida - por exemplo, a acusação de Bárbara Chase Riboud de que Amistad, de Spielberg, roubou cenas de seu romance Echo of Lions, de 1989 - também pode ser vista como uma questão "arquitextual", uma alegação de que o cineasta falhou ao não designar o filme como uma adaptação. (A Dreamworks rebateu com outra inversão transtextual, argumentando que Echo of Lions também não havia se designado como uma "adaptação", já que o livro emprestava material de uma história de 1953, Black Mutiny).

Embora todas as categorias de Genette sejam sugestivas, seu quinto tipo, a "hipertextualidade", é talvez o tipo mais claramente relevante para a "adaptação". A "hipertextualidade" se refere à relação entre um texto, que Genette chama de "hipertexto", com um texto anterior ou "hipotexto", que o primeiro transforma, modifica, elabora ou estende. Na literatura, os hipotextos de Eneida incluem A Odisséia e A Ilíada, enquanto os hipotextos de Ulysses, de Joyce, incluem A Odisséia e Hamlet. Tanto a Eneidae Ulysses são elaborações hipertextuais de um mesmo hipotexto - A Odisséia. Adaptações cinematográficas, nesse sentido, são hipertextos derivados de hipotextos pré-existentes que foram transformados por operações de seleção, amplificação, concretização e efetivação. As várias adaptações cinematográficas de Madame Bovary (Renoir, Minelli, Mehta) ou de AMulher e o Fantoche (Duvivier, von Sternberg, Bunuel) podem ser vistos como variações de leituras hipertextuais disparadas pelo mesmo hipotexto. Quando os romances vitorianos são adaptadores diversas vezes, a própria hipertextualidade se torna um sinal de status canônico; as "cópias", novamente, criam o prestígio do original. De fato, as várias adaptações 
anteriores de um romance podem formar um grande e cumulativo hipotexto disponível para o cineasta que chega relativamente "atrasado" nessa seqüência. Adaptações cinematográficas, desta forma, são envolvidas nesse vórtice de referências intertextuais e transformações de textos que geram outros textos em um processo infinito de reciclagem, transformação e transmutação, sem nenhum ponto claro de origem.

Podemos encontrar um exemplo desse processo em As Aventuras de Robinson Crusoé, um dos romances seminais que serve de fonte para uma tradição européia específica, o romance realista mimético, supostamente baseado na "vida real" e escrito de tal maneira a gerar uma forte impressão de realidade factual. No entanto, esse romance "realista" é em si mesmo um artefato intertextual, enraizado em tradições diversas: a bíblia, a literatura de meditação religiosa, os textos jornalísticos sobre Alexander Selkirk, que foi o protótipo de Crusoé, e a literatura sensacionalista de viagem, apenas para mencionar alguns. $\mathrm{O}$ fato é que qualquer localização específica de origem em última instância se torna enevoada. Defoe se serve de um intertexto anterior e rapidamente se torna envolvido na lógica da seqüência, uma vez que, após o Robinson Crusoé, original de 1719, Defoe logo acrescentou The Farther Adventures of Robinson Crusoe (Mais aventuras de Robinson Crusoé), de 1719 e Serious Reflexions (Reflexões Compenetradas) em 1720. O romance de 1719 também gerou seu próprio "pós-texto". Já em 1805, menos de um século após a publicação do romance de Defoe, uma enciclopédia alemã (Bibliothek der Robinsone) ofereceu um guia abrangente para todos os trabalhos inspirados em Robinson Crusoé. O movimento transtextual ramificou-se então pelo cinema. Começando com o curta de Méliès em 1902, foi realizado um grande número de adaptações em diversos países, chegando até a versão de George Miller/Rod Hardy com Pierce Brosnan em 1996 e Náufrago em 2000.

Madame Bovary, para dar outro exemplo, foi adaptado pelo menos 10 vezes, por diretores da França (Renoir, Chabrol), Portugal (Manoel de Oliveira), Estados Unidos (H. B. Warner, Minnelli), e Índia (Mehta). Cada adaptação joga uma nova luz no romance; Renoir 
transpõe a literaridade de Emma para a teatralidade. Minnelli enfatiza seus sonhos românticos; Chabrol o lugar-comum das províncias. A versão indiana, intitulada Maya (Ilusão) retrata Bovary não apenas através da ótica da filosofia Hindu ("o véu de ilusão") mas também liga o romantismo de Emma, de forma bastante lógica, não ao romantismo literário europeu mas sim às convenções do musical de Bombaim. Assim, Madame Bovary entra no processo contínuo de dialogismo artístico, gerando, após seu surgimento, novos textos, tanto literários quanto cinematográficos, incluindo até textos que não citam explicitamente Madame Bovary. A rosa púrpura do Cairo, de Woody Allen, por exemplo, sendo uma história sobre uma mulher provinciana aprisionada em um casamento opressivo mas sonhando com um romance, pode ser visto como uma atualização cinematográfica de Bovary, na qual os filmes de Hollywood cumprem o papel funcional da literatura romântica. Todas essas transformações transtextuais ilustram a idéia de Genette de que a hipertextualidade reflete a vitalidade de artes que incessantemente inventam novos circuitos de significados a partir de formas mais antigas.

Finalmente, gostaria de fazer algumas propostas modestas para lidar com a narrativa, aspectos temáticos e estilísticos das adaptações cinematográficas, algo menos grandiosamente ambicioso do que uma teoria, porém mais do que uma metodologia. Aqui eu não estarei mais tratando do status teórico da adaptação, mas sim posicionando um modelo prático/analítico para tratar adaptações das propriamente ditas.

Um conjunto de questões sobre adaptação tem a ver com a autoria, e especificamente com as afinidades potenciais entre romancista e cineasta. Embora a crítica biográfica seja provavelmente a mais desacreditada de todas as abordagens críticas nas artes, ainda podemos perguntar se romancista e diretor compartilham de certas afinidades temáticas ou estilísticas. Quando Orson Welles adapta Cervantes, percebemos uma afinidade clara entre o romancista digressivo, paródico e carnavalesco e o cineasta igualmente carnavalesco e paródico. A mesma percepção de uma "combinação" coerente se aplica quando uma cineasta feminista britânica como Sally Potter adapta um texto feminis- 
ta britânico de uma autora como Virginia Woolf. Mas outros exemplos podem parecer, claramente, um casamento infeliz. Por que um surrealista renegado como Buñuel adaptaria um romance puritano, realista e colonialista como Robinson Crusoé? Algumas vezes, o autor e o cineasta entram em conflito aberto, como quando Marguerite Duras expressou fortes objeções à adaptação de Jean-Jacques Annaud do seu romance $O$ Amante. Stephen King, da mesma forma, fez objeções à versão de Kubrick de $O$ Iluminado, e teve sua vingança ao produzir e atuar em uma versão em mini-série na ABC. No campo da especulação, podemos fantasiar combinações perfeitas - Resnais adaptando Proust - ou outras horrendas - Oliver Stone adaptando Marguerite Duras, ou Jerry Lewis adaptando Tolstoy. E há ainda possibilidades intrigantes abertas pela tensão criativa: Chantal Akerman adaptando Lolita, John Sayles adaptando Huckleberry Finn.

Outras questões sobre adaptação têm a ver com as modificações e permutas da história. Aqui nós entramos no campo da narratologia, ou do estudo da mecânica da narrativa. Os narratologistas do cinema se apóiam especialmente na análise narratológica de Genette do tempo do romance. Em seu trabalho literário, Genette enfatiza o duplo esquema do qual o romance de ficção faz parte, ou seja, a relação entre os eventos narrados e a maneira ou sequiência pela qual são contados. Os narratologistas do cinema extrapolaram três das principais categorias de Genette: ordem (que responde à pergunta "quando" e "em que seqüência"), duração (que responde à pergunta "quanto tempo") e freqüência (que responde à pergunta "com que freqüência").

O problema da ordem toca na questão da seqüência linear em contraposição com a não-linear. Uma história pode respeitar a seqüencialidade normal dos supostos eventos "reais", procedendo do início até o meio e o fim, ou ela pode embaralhar essa seqüencialidade. Tanto a versão de Lolita de Kubrick quanto a de Lyne, por exemplo, adotam uma estrutura circular que começa e termina com o assassinato de Quilty por Humbert Humbert, algo revelado gradualmente no romance. Evitar o desenvolvimento linear e alterar a seqüencialidade gera "anacronias", como as analepses (grosseiramente, flashbacks, ou 
memória repentina do passado) e prolepses (grosseiramente, flashforwards, ou premonições). Analepses são ainda divididas em analepses externas (histórias em flashback que voltam para um tempo anterior ao começo da narrativa principal) e analepses internas (que começam num ponto dentro da narrativa principal). Alepses misturadas começam num ponto anterior, mas flexionam ou invadem o "presente" da narrativa principal.

O interesse no sistema um tanto quanto tecnocrático de Genette reside menos no simples nomear desses fenômenos do que em refletir em suas correções com tendências estilísticas. Os filmes noirs, por exemplo, favorecem estratégicas analépticas, geralmente relatadas retrospectivamente através de narradores que não aparecem (Joel Gillis em Crepúsculo dos Deuses). O cine-roman francês, de sua parte, é afeito a prolepses, por exemplo, nas várias premonições em La Guerre est Fini, de Resnais ou La Jetée de Chris Marker, bem como analepses mistas, por exemplo as memórias traumáticas que repetidamente eclodem no "presente" putativo de Hiroshima meu amor.

A "duração" invoca todas as formas complexas de relações entre o tempo do discurso - o tempo que leva para ler o romance ou ver o filme - e as imponderáveis veristas sobre quanto tempo um evento ficcional "realmente" durou. Essa relação define o ritmo da narração. Em termos temporais, algumas adaptações claramente condensam os eventos do romance.Os dois anos retratados no romance O Desprezo, de Moravaia, por exemplo, se transformam nos dois dias da adaptação de Godard, parte de uma teatralização geral do romance. Mudanças como esta têm ligação com o proveitoso conceito de "velocidade" narrativa de Genette (as mudanças de relação entre o tempo da história e o tempo do discurso). Uma adaptação é "mais lenta" ou "mais rápida" do que o romance em termos de densidade de incidente e ritmo da ação? Exposição eficiente, densidade de informações no plano, movimentação rápida dentro da tomada, diálogos executados em staccato, tudo isso contribui para um senso de velocidade no cinema.

Genette propõe uma ficção analítica ou norma chamada "velocidade constante" para sugerir uma velocidade normal, relativamente 
estável da narrativa em relação à qual uma dada passagem seria "rápida" ou "lenta". A velocidade máxima em relação a essa norma imaginária é a elipse, na qual eventos principais e secundários são pulados. No filme hollywoodiano clássico, a elipse forma parte da edição normal (analítica) e encenação que nos fornece uma seleção altamente criteriosa dos eventos. Uma refeição hollywoodiana clássica, por exemplo, poderia consistir em algumas colheradas de sopa, algumas mordidas de bife, e alguns fragmentos de conversação. A velocidade mínima é a pausa descritiva, uma espécie de suspensão do tempo da história, na qual a ficção como que pára no meio do caminho. Um exemplo cinematográfico poderia ser as demoradas e estáticas tomadas de objetos em Muriel, de Resnais. Em cena, com suas nuances teatrais, o tempo do discurso narrativo coincide com o tempo da história imaginada na diegese. Resumindo, o tempo do discurso é menor do que o tempo da história. Um exemplo cinematográfico pode ser a breve seqüência de montagem em Cidadão Kane, que relata a ascensão e queda meteóricas da cantora de ópera Susan Alexander. (Christian Metz usou as categorias de Genette como uma base parcial para seu próprio "grande syntagmatique" (N.T. Em francês no original) do tempo da imagem, uma tentativa de conferir alguma precisão à discussão de tempo e espaço nos filmes de ficção).

A freqüência, finalmente, se refere à relação entre quantas vezes um evento ocorre na história e quantas vezes ele é narrado (ou mencionado) no discurso textual. Genette postula três variantes principais: 1) narração singulativa (um único evento é contado uma única vez, a norma na maioria dos filmes de ficção); 2) narração repetitiva (um evento é relatado muitas vezes, nas narrações multi-perspectivas, como ocorre em Rashomon); 3) narração iterativa (um evento que ocorreu diversas vezes é relatado uma vez); e 4) um evento que ocorreu diversas vezes é relatado diversas vezes, o que eu chamaria de narração homóloga. Mas tanto o cinema quanto o romance oferecem uma possibilidade não mencionada por Genette que combina 1) e 2), que poderia ser chamada de "narração cumulativa", ou seja, casos onde um único evento casual é gradualmente detalhado através de 
memórias repentinas (flashbacks) mostradas repetidamente ao longo do filme, por exemplo os eventos traumáticos que deram origem à cleptomania de Marnie no filme Marnie, de Hitchcock, ou a amnésia provocativa de Ballantine em Spellbound.

Por meio de exemplo, podemos elaborar apenas um dos tipos de Genette - o iterativo. O iterativo no romance evoca o imperfeito na prosa Flaubertiana, o tempo da repetição habitual, e especificamente o tratamento dado pelo romance ao tédio no que Flaubert chamou de "um livro sobre nada". Nesse mesmo espírito, o teórico/ cineasta italiano neo-realista Cesare Zavattini sonhou em filmar noventa minutos na vida de uma pessoa a quem nada acontecia. Andy Warhol filmou um homen dormindo e o Empire State Building enquanto permanecia "em pé". Mas qual seria o meio cinematográfico ideal para evocar o enfado que permeia um romance como Madame Bovary? O tempo literal de duração de um longo plano seqüência, onde a lentidão do tempo real exprimiria a passagem do tempo, que se arrasta como uma cobra (uma técnica usada por Santos em Vidas Secas)? Ou deveriam os personagens comentar verbalmente o seu tédio (a solução de Minnelli), ou lançar mão de narração por superposição (em voice-over) para literalmente emprestar as palavras que evocam o tédio no romance (a solução de Chabrol)? Ou deveria-se usar o que Metz chama de "seqüência episódica" (cenas curtas mostrando uma certa trajetória, nesse caso uma trajetória em direção ao tédio, sendo um exemplo famoso disso a seqüência de desintegração do casamento numa série de desjejuns em Citizen Kane). Outra abordagem seria através da metonímia visual: uma torneira pingando para transmitir a idéia da passagem lenta e repetitiva do tempo; ou câmera lenta, ou a dilatação de uma tomada pela edição (na qual o mesmo gesto é repetido ad infinitum), ou um gesto sinedóquico (por exemplo o ato de rabiscar distraidamente). Cada abordagem tem suas vantagens e desvantagens.

Uma vez que a adaptação envolve dois textos que presumivelmente comunicam a mesma narrativa, ela necessariamente traz à tona algumas questões não mencionadas por Genette. Isso se torna, portanto, uma questão de narratologia comparativa, que faz perguntas 
do tipo: Que eventos da história do romance foram eliminados, adicionados, ou modificados na adaptação e, mais importante, por quê? Embora o filme de ficção tenha evoluído bastante desde as versões silenciosas de 5 minutos de romances como L'Assomoir, de Zola, as adaptações hoje tipicamente ainda aparam os eventos do romance para produzir um longa metragem de duração "normal". O escritor Milan Kundera, pelo que se diz, deu a Philip Kaufman apenas uma palavra como conselho no que diz respeito à adaptação de $A$ Insustentável Leveza do Ser- "elimine!" Muitos cineastas, nesse mesmo espírito, "dinamizam" o romance focando em certos personagens e eventos em detrimento de outros. A maioria das versões cinematográficas de Robinson Crusoé, por exemplo, pula os capítulos iniciais de modo a avançar para o que eles vêem como os elementos "centrais" da história: o naufrágio, a ilha, o encontro com Sexta Feira. A maioria das versões de Madame Bovary omite o primeiro casamento de Charles para fechar o foco em Emma.

À parte dos personagens e eventos, muitas adaptações eliminam tipos específicos de materiais, notavelmente aquilo que é visto como não estando diretamente relacionado com a história e, portanto, visto como prejudicial para a progressão da narrativa: os comentários críticoliterários de Don Quixote ou Tom Jones, os ensaios intercalados em As Vinhas da Ira. Algumas vezes, surpreendentemente, eliminações podem não ser intencionais. Quando Kubrick adaptou Laranja Mecânica de Anthony Burgess, ele trabalhou com uma edição americana (e não britânica) do romance na qual estava faltando o capítulo final, com a epifania do protagonista. Outras vezes, os diretores alteram eventos, como quando Minnelli, provocando Flaubert, faz com que Charles Bovary se recuse a realizar a operação em Hippolyte.

Ou os cineastas podem simplesmente amplificar passagens do romance que oferecem possibilidades tentadoras para tomadas espetaculares ou "cinematográficas". Desta maneira, uma breve mensão do amor de Squire Western pela caça, em Tom Jones de Fielding, se torna no filme uma longa e elaborada seqüência de caça, com cavalos galopantes e tomadas voadoras de grua. Alguns diretores adicionam 
materiais simplesmente para seu próprio prazer, como quando Truffaut inclui a canção "Le Tourbillon de la Vie", interpretada por Jeanne Moreau em Jules e Jim. Em ocasiões muito raras, um diretor descarta a maioria dos eventos do romance que serve de fonte e constitui o filme unicamente a partir de novos materiais, como é o caso de Masculino, Feminino, de Godard, presumivelmente baseado em uma história de Guy de Maupassant mas que traz pouco mais do que o nome dos personagens do romance.

Uma narratologia comparativa da adaptação também examina as formas como as adaptações adicionam, eliminam ou condensam personagens. Dr. John Ray, o "personagem" que introduz as memórias de Humbert no romance de Nabokov, é acolhido no roteiro de Nabokov, mas eliminado sem a menor cerimônia do filme de Kubrick. Algumas vezes uma constelação de grupos de personagens são reduzidos para um único grupo; as várias famílias Okie em Vinhas da Ira, de Steinbeck, se tornam uma única família, a família Joad. Ou um único personagem em um filme pode acumular traços de vários personagens do romance, como ocorre quando Truffaut, em sua adaptação de Jules e Jim, de Roche, amalgama características de toda uma galeria de mulheres do romance para moldar a personagem Catherine, uma condensação de traços que acentua ainda mais nossa percepção de sua ambiguidade mercurial. Algumas vezes as adaptações adicionam personagens. Godard adiciona a tradutora Francesca em sua adaptação de O Desprezo, de Moravia. Minnelli adiciona "Flaubert" como personagem em sua versão de Madame Bovary. Personagens também podem ser alterados em termos de sua identidade étnica, como ocorre quando o juiz branco de Fogueira das Vaidades é transformado em um juiz negro interpretado por Morgan Freeman, parcialmente, talvez, como uma salvaguarda contra a acusação de racismo lançada contra o romance de Tom Wolfe. O problema que importa para os estudos da adaptação é que princípio guia o processo de seleção ou "triagem" quando um romance está sendo adaptado? Qual é o "sentido" dessas alterações? 


\section{Além do formalismo}

A narratologia é uma ferramenta indispensável para analisar certos aspectos formais das adaptações ao cinema. Mas o formalismo, que Edward Said compara em Cultura e Imperialismo com "descrever a estrada sem a paisagem", corre o risco de excluir uma análise histórica mais profunda do assunto em questão. Um importante conjunto de questões relativas às adaptações tem a ver com o contexto. A palavra "con-texto", etimologicamente, implica em elementos que vão "junto" ou "ao longo" do texto. Mas "ao longo" é de certa forma uma metáfora espacial que induz ao erro, já que texto e contexto são inseparáveis em última instância, "mutuamente invaginados" (nos termos de Derridá); há, entre os dois, uma membrana permeável (nos termos de Bakhtin).

Um tipo de contexto é o temporal. Em alguns casos, a publicação do romance e a produção do filme ocorrem em momentos muito próximos e diretos. No caso dos mais vendidos, os produtores se apressam para tirar vantagem do sucesso comercial do romance. A produção do filme Vinhas da Ira, de John Ford, começou apressadamente, logo após a publicação do livro de John Steinback, e foi de fato lançado menos de um ano depois da publicação. A adaptação de Spielberg para A Cor Púrpura, similarmente, foi lançada apenas três anos depois do romance de Alice Walker, e logo se enredou numa série de polêmicas da atualidade relacionadas com o momento do lançamento, quais sejam: 1) identidade (pode um diretor branco adaptar um romance escrito por uma negra?); 2) o cânon (que obras literárias deveriam ser ensinadas na escola?); 3) raça e gênero (o filme demoniza os negros?); e 4) premiações do Oscar (o racismo, ou um preconceito anti-Spielberg, impediu o filme de arrebatar mais Oscars?).

Em outros casos, séculos ou mesmo milênios podem passar entre a publicação do romance original e a produção da adaptação, que é o caso de adaptações como Satyricon de Fellini ou o Decameron de Pasolini. As adaptações de romances como Don Quixote e Robinson Crusoé são necessariamente filmadas séculos depois do original. Conseqüentemente, o adaptador desfruta de mais liberdade para atualizar 
e re-interpretar o romance. A existência de tantas adaptações anteriores alivia a pressão pela "fidelidade", ao mesmo tempo em que estimula a necessidade de inovação. Às vezes o adaptador inova para fazer com que a adaptação fique mais "sincronizada" com os discursos contemporâneos. A recente adaptação de Palácio das Ilusões visiona o romance de Jane Austen "através" da crítica pós-colonial à la Edward Said, colocando em primeiro plano a escravidão caribenha, que era deixada para segundo plano no romance de Jane Austen. Muitas adaptações revisionistas de romances vitorianos, ao mesmo tempo, os "desreprimem" em termos sexuais e políticos. Uma dinâmica de liberação feminista e sexual desprende a libidinosidade subliminar e o espírito feminista latente dos romances e dos personagens, ou até mesmo do autor, em um tipo de terapia anacrônica ou resgate adaptacional da fantasia. Adaptações pós-coloniais de romances como Robinson Crusoé, ao mesmo tempo, liberam retroativamente os personagens coloniais oprimidos do original.

O termo "contexto" também evoca problemas de censura, seja externa ou interna, consciente ou inconsciente. Deste modo, na adaptação do romance Vinhas da Ira foi suprimido, não apenas as passagens mais explicitamente "socialistas", mas também o naturalismo chocante das cenas onde Rosasharn amamenta um homem faminto. No caso de Madame Bovary, Minnelli começa sua adaptação com a encenação do julgamento por obscenidade do romance de Flaubert, como se quisesse avisar os censores contemporâneos que eles não deveriam ter uma visão tão restrita quanto seus colegas filisteus. A censura também reage especificamente a cada meio; a escrita, como o romance, geralmente recebe maiores concessões em termos de liberdade sexual do que um veículo de massa como o cinema. Tais considerações inevitavelmente "colorem" a representação. Ambas as versões cinematográficas de Lolita tiveram que brigar com a ameaça, e a realidade, da censura. Trabalhando no severo período pós-Mccarthy e pós-guerra, Kubrick internalizou o espírito da censura de tal forma que em determinado momento ele e o roteirista James Harris contemplaram fazer com que Humbert casasse com Lolita - a família valoriza o incesto - com a 
bênção de um parente adulto. ${ }^{9}$ Décadas depois, a versão de Adrien Lyne teve de enfrentar preocupações generalizadas sobre pedofilia e pornografia infantil. Mas as adaptações também podem fazer com que a fonte fique ainda mais ousada. Dessa forma a saborosamente eufemística circunlocução de Henry James dá lugar aos deleites carnais de Retrato de uma Dama, de Campion, no qual Isabel fantasia estar sendo acariciada por Goodwood, Ralph Touchette Lord Warburton, todos ao mesmo tempo; um drama de época se transforma num drama onde os personagens se despem (N.T. O autor faz um trocadilho com a palavra costume drama (drama de época) e disrobing drama (adjetivo derivado de disrobe, termo formal para o ato de despir-se). A versão de Minghella para O Talentoso Sr. Ripley, uma história de Patrícia Highsmith, da mesma forma, é mais explícita sobre a homossexualidade do que o romance, bem como a adaptação anterior, O Sol por Testemunha.

Muitas das mudanças entre a fonte do romance e a adaptação cinematográfica têm a ver com ideologia e discursos sociais. Nesse sentido, a questão é se uma adaptação empurra o romance para a "direita", ao naturalizar e justificar hierarquias sociais baseadas em classe, raça, sexualidade, gênero, religião e nacionalidade, ou para a "esquerda" ao questionar ou nivelar as hierarquias. Há também "desenvolvimentos desiguais" a esse respeito, por exemplo, em adaptações que empurram o romance para a esquerda em algumas questões (como classe) mas para a direita em outras (como gênero e raça). Adaptações cinematográficas freqüentemente "corrigem" ou "melhoram" o texto original, de formas muito diferentes e até contraditórias. Os filmes contemporâneos de Hollywood tendem a ser fóbicos em relação a qualquer ideologia vista como "extrema", seja ela proveniente da esquerda ou da direita. As adaptações hollywoodianas freqüentemente "corrigem" suas fontes ao extrair delas o que é controverso - como o lesbianismo em A Cor Púrpura - ou revolucionário - como o socialismo em Vinhas da Ira - ou difícil - como a técnica reflexiva em Lolita - ou anticinematográfico - as passagens filosóficas em Moby Dick. A "cena da reconciliação" entre Shug e seu pai pregador, em ACor Púrpura, de Spielberg, uma cena que não existe no romance, joga o filme numa 
direção mais patriarcal, ao fazer com que Shug seja menos bissexual, rebelde e independente.

Muitas adaptações televisivas ou das tendências dominantes de Hollywood fazem o que pode ser chamado de uma "adequação estética às tendências dominantes". Os vários manuais populares sobre como escrever roteiros e adaptações são bastante esclarecedores nesse sentido. Seja qual for o romance original, a maioria dos manuais mostram uma aversão radical a todas as formas de experimentação e modernismo. Quase invariavelmente, eles recomendam jogar a fonte na direção do modelo dominante de contar histórias (seja no modelo clássico de Hollywood ou de Sundance, sua versão mais amenizada). O modelo aristotélico reciclado e suburbanizado dos manuais de roteiro recorrem a estruturas em três atos, conflitos principais, personagens coerentes (e muitas vezes simpáticos), um "arco" narrativo inexorável e catarse final ou final feliz. Geralmente, a premissa básica desse esquema é o combate entre personagens altamente motivados e cheios de possibilidade de agir, um paradigma cuja premissa é, frequentemente, a "hostilidade constante" entre as pessoas, como mostra Raoul Ruiz. Tudo se torna subordinado a uma teleologia tão implacável quanto o destino da tragédia clássica. O objetivo parece ser "desliteralizar" o texto, uma vez que o romance passa por uma máquina de adaptação que remove todas as excentricidades autoriais ou os "excessos". A adaptação é vista como uma espécie de purgação. $O$ romance, em nome da legibilidade para a audiência das massas, é "purificado" das ambigüidades morais, interrupções narrativas e meditações reflexivas. A corrente estética dominante é compatível com a censura econômica, já que as mudanças exigidas numa adaptação são feitas em nome da soma de dinheiro gasta e dos lucros esperados.

Adaptações de romances de outros períodos confrontam o cineasta com a escolha de criar um drama de época ou atualizar o romance para o período contemporâneo. Obras de época apresentam desafios especiais, não apenas em termos de reconstruir uma era, mas também em termos de evitar anacronismos temporais tais como antenas de TV na Inglaterra vitoriana ou aviões nos céus da França revolucionária. 
(Truffaut disse uma vez que se ele soubesse quão difícil é fazer filmes de época, ele não teria situado Jules e Jim no passado). Mas aqui uma distinção importante às vezes não é observada: alguns romances começam como dramas de época, no sentido de que são situados no passado mesmo, vis-à-vis o tempo de produção do romance (o caso de Memórias Póstumas de Brás Cubas, de Machado de Assis). Outros romances, no entanto, se tornam dramas de época apenas pela passagem do tempo desde a publicação do romance. Lolita, de Kubrick, realizado apenas sete anos depois da publicação do romance de Nobokov, não é uma obra de época, mas Lolita de Lyne, realizado mais de três décadas depois, é uma obra de época, que usa música popular e assessórios do período para situar a história no final da década de 1940 e início da década de 1950. Algumas adaptações apenas se deslocam em direção ao presente. A adaptação de Notas do Submundo (1980), de Sarquis, desloca o romance de Dostoevski para frente no tempo, mas apenas para a década de 1930. As adaptações de The Merchant-Ivory para autores como Henry James (Os Bostonianos) e E. M. Foster (Uma Janela para o Amor), são todos filmes de época, bem como a maioria das adaptações de JaneAusten (Emma, Orgulho e Preconceito, Palácio das Ilusões), mas As Patricinhas de Beverly Hills é uma atualização, bem como Grandes Esperanças (1988) de Alfonso Cuaron. Alguns romances, como Ligações Perigosas, de Laclos, já foram adaptados tanto como filmes de época como atualizações. Duas das versões, Ligações Perigosas (1988), de Frear, e Valmont - Uma História de Seduções (1989), de Forman, são filmes de época, mas as versões de Roger Vadim e Roger Kumble são atualizações. Em 1960, Vadim reposicionou o romance na Paris pós-guerra da nouvelle vague, transformando a libertina de Laclo em uma "mulher liberada" desfrutando de um "casamento aberto". Mais recentemente, em Segundas Intenções, Kumble transpôs o romance para a Manhattan comtemporânea, remodelando os adultos de Laclos para adolescentes de classe alta. Ao invés de aproveitar o e-mail como um equivalente contemporâneo da correspondência do século XVIII, Kumble faz com que Valmont descarte o e-mail como "coisa de viciados em tecnologia e pedófilos". 
Como os dois últimos exemplos sugerem, as adaptações são invariavelmente inscritas em cenários nacionais. As adaptações se situam no mesmo local que o romance, ou a localidade muda? Coppola transforma a floresta africana de No Coração das Trevas, de Conrad, na floresta vietnamita de Apocalipse Now. Kubrick, em De Olhos Bem Fechados, transforma a Viena do século XIX da Dream Story, de Schnitzler, em uma estranha versão alternativa da Manhattan contemporânea. As Patricinhas de Beverly Hills transpõe a Highwood do século XIX de Austen para a Beverly Hills do século XX. Se o romance enquanto gênero permite a completa flexibilidade de criação pela qual o escritor pode evocar tempos passados ou locais "exóticos" com os traços da caneta, o cinema tem de trabalhar mais arduamente. Mas ele também desfruta de um recurso não disponível para o romance - a possibilidade de usar locações reais, como, por exemplo, as propriedades no campo disponíveis para as adaptações de Jane Austen ou as mansões e residências disponíveis para os filmes baseados em Henry James. Além do mais, nada impede que um filme multiplique as locações ao: a) evocar verbalmente lugares distantes ou b) lançar mão de recursos Brechtinianos (como o cartão postal para Nova Iorque e Egito em Tempo de Guerra, de Godard) ou c) usar as novas mídias digitais para construir lugares distantes.

Muitas adaptações são trans-nacionais: Minnelli adapta Flaubert; Claire Denis adapta Melville; Visconti adapta Thomas Mann; Bresson adapta Dostoievsky. A questão das adaptações transnacionais traz consigo questões de língua e sotaque. O que acontece quando um romance situado na França como Madame Bovary é adaptado em Hollywood por um diretor americano como Minnelli ou em Bombaim por um indiano como Mehta? O que acontece com a língua francesa? No filme de Minnelli, os atores falam um híbrido bizarro, seja de inglês com sotaque francês (Louis Jourdain como Rodolphe) ou um inglês afrancesado com pitadas de palavras francesas como "Bonjour" e "Monsieur".

Com as coproduções internacionais, o "cenário" linguístico e nacional se torna ainda mais incerto. Doutor Jivago, por exemplo, foi baseado num romance russo, filmado na Espanha, mas com a atuação de 
atores egípcios (Omar Sharif) junto com ingleses (Julie Christie) falando inglês. Na era da globalização, a localidade nacional sofre o impacto das preocupações prevalentes com o lucro e o custo-benefício. Embora Moby Dick de Melville já fosse global em seu escopo e implicações, apresentando viagens pelo mundo e a tripulação multi-cultural do Pequod, a adaptação de 1988 da USA Network era globalizada. Embora o canal a cabo e o romance fossem americanos, o filme era uma coprodução australiana/inglesa cujo objetivo era tirar vantagem das taxas de câmbio, do baixo custo de mão de obra e dos incentivos fiscais. Alguns cineastas, felizmente, transformam a "internacionalidade" em um recurso creativo. Esse Obscuro Objeto do Desejo- um filme de um diretor espanhol (Buñuel), que freqüentemente trabalhava na França, que é uma adaptação de um romance de um francês (Louiys), que escreveu sobre a Espanha, no qual, no entanto, o principal personagem espanhol (Mateu) se transforma em um francês (Mathieu), mas é interpretado por um famoso ator espanhol (Fernando Rey), enquanto a performance é dublada por um conhecido ator francês (Michel Piccoli). Ocorre aí um jogo de tensões entre "francesidade" e "espanholidade", tensões essas já presentes no romance como uma manifestação de exotismo francês e espanófilo.

Já que as adaptações fazem malabarismos entre múltiplas culturas e múltiplas temporalidades, elas se tornam um tipo de barômetro das tendências discursivas em voga no momento da produção. Cada recriação de um romance para o cinema desmascara facetas não apenas do romance e seu período e cultura de origem, mas também do momento e da cultura da adaptação. Os textos evoluem sobre o que Bakhtin chama de "o grande tempo" e freqüentemente eles passam por "voltas" surpreendentes. "Cada era", escreve Bakhtin, "reacentua as obras [do passado] de sua própria maneira. A vida histórica de trabalhos clássicos é de fato o processo ininterrupto de sua reacentuação" ${ }^{12}$ A adaptação, nesse sentido, é um trabalho de reacentuação, pelo qual uma obra que serve como fonte é reinterpretada através de novas lentes e discursos. Cada lente, ao revelar aspectos do texto fonte em questão, também revela algo sobre os discursos existentes no momento da 
reacentuação.Ao revelar os prismas e discursos através dos quais o romance foi reimaginado, as adaptações fornecem aos próprios discursos um tipo objetivo de materialidade.

\section{Conclusão}

Se o estudo das adaptações parece, à primeira vista, uma área relativamente desprezada dentro da teoria e análise cinematográfica, por outro lado ele também pode ser visto como algo central e importante. Não apenas as adaptações literárias formam uma alta porcentagem dos filmes já realizados (e, especialmente, uma alta proporção das produções de prestígio e ganhadores do Oscar), mas também todos os filmes podem ser vistos, de certo modo, como "adaptações". Embora o estudo das adaptações freqüentemente assuma que os textos-fonte são literários, as adaptações também podem ter fontes sub-literárias ou para-literárias. Filmes históricos como Reds adaptam textos históricos. Filmes biográficos adaptam textos biográficos sobre figuras históricas famosas. Alguns filmes, como O Homem Errado, de Hitchcock, adaptam reportagens de jornal. Um filme como $O$ Homem Aranha adapta uma história em quadrinhos. Veja Esta Canção, de Carlos Diegues, adapta músicas populares brasileiras. Outros filmes (como A Guerra dos Meninos, de Gilberto Dinnerstein) adaptam trabalhos de não-ficção ou como Wittgenstein, exploram a vida e obra de um filósofo ou de um pintor (Pollock) ou um escritor (Íris). Até mesmo as não-adaptações adaptam um roteiro. A questão é que praticamente todos os filmes, não apenas as adaptações, re-filmagens e seqüências, são mediadas através da intertextualidade e escrita. A lei de direitos autorais fala em "obras derivadas", ou seja, obras que "remodelam, transformam ou adaptam" algo que veio antes. Mas as adaptações, de certa forma, tornam manifesto o que é verdade para todas as obras de arte - que elas são todas, em algum nível, "derivadas". E, nesse sentido, o estudo das adaptações causa potencialmente um impacto na nossa compreensão de todos os filmes. 
No caso das adaptações cinematográficas dos romances, para resumir o que foi argumentado até aqui, o romance original ou hipotexto é transformado por uma série complexa de operações: seleção, amplificação, concretização, atualização, crítica, extrapolação, popularização, reacentuação, transculturalização. O romance original, nesse sentido, pode ser visto como uma expressão situada, produzida em um meio e em um contexto histórico e social e, posteriormente, transformada em outra expressão, igualmente situada, produzida em um contexto diferente e transmitida em um meio diferente. $O$ texto original é uma densa rede informacional, uma série de pistas verbais que o filme que vai adaptá-lo pode escolher, amplificar, ignorar, subverter ou transformar. A adaptação cinematográfica de um romance faz essas transformações de acordo com os protocolos de um meio distinto, absorvendo e alterando os gêneros disponíveis e intertextos através do prisma dos discursos e ideologias em voga, e pela mediação de uma série de filtros: estilo de estúdio, moda ideológica, constrições políticas e econômicas, predileções autorais, estrelas carismáticas, valores culturais e assim por diante. Uma adaptação consiste em uma leitura do romance e a escrita de um filme. O hipertexto cinematográfico, nesse sentido, é transformacional quase no sentido Chomskiano de uma "gramática generativa" da adaptação, com a diferença de que essas operações, através de diferentes meios, são infinitamente mais imprevisíveis e multi-fatoriais do que elas seriam se fosse o caso de uma "linguagem natural". Em termos não-linguísticos, numa linguagem mais Deleuziana, as adaptações redistribuem energias, provocam fluxos e deslocamentos; a energia lingüística do texto literário se transforma em energia áudio-visual-cinética-performática da adaptação.

A linguagem convencional do crítico das adaptações ("infidelidade", "traição", assim por diante), para voltar ao nosso ponto inicial, traduz nossa decepção de que uma versão cinematográfica de um romance não conseguiu ter o impacto moral ou estético desse romance. Ao adotar uma abordagem intertextual em oposição à uma abordagem que faz julgamentos baseados em suposições sobre a putativa superio- 
ridade da literatura, nós não abandonamos todas as noções de julgamento e avaliação. Mas nossa discussão será menos moralista, menos comprometida com hierarquias não admitidas. Nós ainda podemos falar em adaptações bem feitas ou mal feitas, mas desta vez orientados não por noções rudimentares de "fidelidade" mas sim, pela atenção à "transferência de energia criativa", ou às respostas dialógicas específicas, a "leituras" e "críticas" e "interpretações" e "re-elaboração" do romance original, em análises que sempre levam em consideração a lacuna entre meios e materiais de expressão bem diferentes.

\section{Notas}

1. Uma versão bem mais curta e bem diferente deste ensaio foi publicada em Film Adaptation, a elogiada coleção de James Naremore, (New Brunswick: Rutgers University Press 2000). Uma versão ligeiramente diferente do mesmo ensaio foi publicada pela Udine Film Conference. Eu gostaria de agradecer as várias platéias - University of California, Santa Cruz, na Udine Conference, na Itália, na University of Tel Aviv - que deram retorno sobre alguns desses materiais.

2. Citado em Kamilla Elliot, Through the Looking Glass (2001), uma dissertação escrita para o Departamento de Inglês da University of California, Berkeley.

3. O pós-modernismo de Lyotard, curiosamente, é formulado como uma espécie de anti-narratologia, como o declínio das "grandes narrativas" em favor de pequenas histórias ou "petits recits" mais relativizados, da mesma forma que o cineasta Claude Chabrol recomendava o tratamento de "pequenos assuntos", um amor suburbano ao invés de Fabrice em Waterloo.

4. Vide Kamilla Eliot, op. cit., capítulo quatro, página 25. Elliot desenvolve uma taxonomia muito útil de modelos para falar sobre adaptação: 1) mediúnico (a passagem do espírito do texto); 2) ventriloquista (a imposição de uma nova voz num corpo inerte); 3 ) genético (um DNA textual profundo é manifestado de forma nova em uma nova realidade); 4) de(re)composição (o romance é decomposto em partes e recomposto em outro nível); 5) encarnacional (a palavra se torna carne); e trunfada (o filme mostra suas capacidades superiores para contar a história). 
5. Para uma exploração sistemática, até mesmo técnica, da adaptação enquanto tradução, vide Patrick Cattrysse, Pour une Theorie de 1"Adaptation Filmique: Le Film Noir Americain (Berne: Peter Lang, 1992).

6. Vide Peter Bart, "Attack of the Clones," GQ (September 2002).

7. Vide Stephen Schiff, Lolita: The Book of the Film (New York: Applause, 1998).

8. "Screening Copyright and Pirate Hollywood," capítulo da dissertação em andamento para o Cinema Studies Department na New York University.

9. Vide Brian Boyd, Vladimr Nabokov: The American Years (Princeton: Princeton University Press, 1991, p. 387).

10. Vide Raoul Ruiz, Poetics of Cinema (Paris: Editions Dis Voir, 1995).

11. Sid Field, Screenplay: the Foundations of Screenwriting (New York: Dell, 1979, p. 56).

12. M. M. Bakhtin, "Discourse in the Novel," in The Dialogical Imagination Trans. Caryl Emerson and Michael Holquist (Austin: University of Texas Press, 1981, p. 421).

\section{Referências}

BAKHTIN, Mikhail Mikhailovich. "Discourse in the Novel". In The Dialogical Imagination. Trad. Caryl Emerson e Michael Holquist. Austin: University of Texas Press, 1981. p. 259-422.

BOYD, Brian. Vladimr Nabokov: The American Years. Princeton: Princeton University Press, 1991.

CATTRYSSE, Patrick. Pour une Theorie de 1"Adaptation Filmique: Le Film Noir Americain. Berne: Peter Lang, 1992.

ELLIOT, Kamilla. "Through the Looking Glass." Tese (Doutorado) - University of California, 2001.

FIELD, Sid. Screenplay: the Foundations of Screenwriting. New York: Dell, 1979. 
NAREMORE, James. Film Adaptation. New Brunswick: Rutgers University Press, 2000.

RUIZ, Raoul. Poetics of Cinema. Paris: Editions Dis Voir, 1995.

SCHIFF, Stephen. Lolita: The Book of the Film. New York: Applause, 1998. 